\title{
MASACRES Y TRATAMIENTO INFORMATIVO EN COLOMBIA: LA PLANIFICACIÓN DEL SILENCIO
}

\author{
MASSACRES AND NEWS COVERAGE IN COLOMBIA: THE \\ PLANIFICATION OF SILENCE. \\ MASSACRE E COBERTURA JORNALÍSTICA NA COLÔMBIA: O \\ PLANEJAMENTO DO SILÊNCIO
}

Por:

Patricia Alzate Jaramillo

Profesora Asistente

Escuela de Comunicación Social

Universidad del Valle

patricia.alzate@correounivalle.edu.co

Resumen: Este artículo tiene como propósito explorar una perspectiva de análisis mediático que involucre de manera más explícita las correlaciones entre el análisis textual, el contexto social y la práctica del periodismo. De manera específica, hace un análisis comparativo entre tres medios impresos de orden local, regional y nacional (El Puerto, El País y ElTiempo) sobre el tratamiento informativo de dos masacres ocurridas en el corregimiento de Sabaletas (municipio de Buenaventura) en los años 2000 y 2003.

El trabajo parte de la hipótesis de que el silencio informativo adquiere diferentes facetas y que, así como al no decir, se está diciendo, también al decir, se está omitiendo.

Palabras claves: Masacres Valle del Cauca, periodismo y masacres, Análisis de medios. 
Abstract: This article has the purpose to explore a perspective of media analysis that involves in a more explicit way the correlations between textual analysis, social context, and the journalist practice. More specifically, it makes a comparative analysis between three printed publications, of local, regional and national nature (El Puerto El Pais and El Tiempo) and the way they covered two massacres that took place in the village of Sabaletas (municipality of Buenaventura) in the years 2000 and 2003. The work is based on the hypothesis that media silence takes on different facets and that, as to not say, is saying, also when saying it, it is being omitted

Keywords: Massacres in Valle del Cauca, Journalism and Massacres, Media Analysis.

Resumo: Este artigo tem o propósito de explorar uma perspectiva de análise mediática a qual envolve de maneira más explícita as correlações entre a análise textual, o contexto social e a prática do jornalismo. De maneira específica, o artigo faz uma análise comparativa entre três meios impressos de natureza local, regional e nacional (El Puerto, El País e El Tiempo) sobre a cobertura de dois massacres ocorridos nos anos 2000 e 2003. O trabalho tem origem na hipótese de que o silêncio jornalístico adquire diferentes facetas; e que calar é dizer, ao mesmo tempo que dizer também é uma maneira de omitir.

Palavras-chave: Massacres, Valle del Cauca, Jornalismo e Massacres, Análise de Mídia.

\section{INTRODUCCIÓN}

La herramienta básica para la construcción de información es el lenguaje, de ahí que para el periodismo la importancia de nombrar correctamente las cosas y de explicitar desde dónde se dicen debería considerarse un compromiso esencial. Nada más difícil. El hecho de nombrar las cosas y más aún, de hacerlo correctamente, ha estado mediado históricamente por una serie diversa de factores internos y externos a las lógicas de producción de información. Todo ello conlleva a que una suerte extensa de temas quede excluida parcial o totalmente de la agenda mediática masiva y que, en consecuencia, su posicionamiento en la opinión pública sea relegado a un plano secundario o ni siquiera aparezca. En ese sentido, es importante analizar el periodismo y los medios de comunicación no solamente desde lo que dicen - lo que nombran- sino también desde lo que omiten. Pero ¿cómo analizar lo que no ha sido dicho? Alex Grijelmo (2012), en un libro dedicado al silencio de la información, se refiere al reconocimiento del "silencio periodístico expresivo" como un recurso para decir, sin decir (p.44). Ese vacío entre lo dicho y lo no dicho puede intentar ser llenado a partir del análisis del contexto: de los periodistas y sus medios, de los actores que integran la realidad social convertida o no en acontecimiento informativo, y de sus eventuales receptores. 
Este trabajo hace una apuesta en ese sentido, específicamente en el contexto del conflicto armado colombiano y de la violencia cometida contra la población civil por medio de las masacres. Qué contexto más propicio para reflexionar sobre el silencio informativo. Frente a la cifra de al menos 1.982 masacres documentadas por el Grupo de Memoria Histórica GMH (2013) entre 1980 y 2012 se constituye en una tarea titánica pretender dar cuenta de cómo fue el tratamiento de las mismas en los diferentes medios de comunicación de orden regional y nacional. Este documento es muchísimo más modesto. Intenta explorar ese análisis a partir de un par de casos muy específicos y, comparado con otras tragedias, de menor envergadura en términos numéricos, pero no en consecuencias para la comunidad. Se trata de dos masacres sucedidas entre los años 2000 y 2003 en el poblado de Sabaletas, corregimiento No. 8 del municipio de Buenaventura (a 40 minutos aproximadamente de su casco urbano), compuesto por un total de 16 veredas dispersas a lo largo del río Sabaletas y de la selva húmeda tropical del pacífico colombiano. En este corregimiento, a partir de los años 80 se generaron dinámicas vinculadas a la presencia progresiva de narcotraficantes, insurgentes (Frente 30 de las FARC), paramilitares y fuerza pública. La resonancia de los hechos de violencia a nivel nacional fue mínima frente a las consecuencias que las mismas tuvieron en la población civil (desplazamientos, miedos, desintegración de vínculos sociales, etc.)

Los medios escritos analizados son el periódico local El Puerto (Buenaventura), el regional El País (Cali) y el Tiempo, del nivel nacional; esta selección busca indagar de qué manera incide la mayor o menor cercanía a los hechos en su tratamiento informativo. La selección del caso de Sabaletas se debió a la posibilidad de acceder a documentos escritos y experiencias de periodistas que daban cuenta de la historia de la región y del modo como los eventos sucedidos a lo largo de más de dos décadas afectaron su vida social y cultural. Fueron fundamentales en este sentido los siguientes documentos: Identidad e imágenes, Sabaletas un pueblo con memoria, documento que sistematiza el proceso de intervención social realizado por la Misión de Apoyo al Proceso de Paz de la OEA Mapp- OEA (2011). La monografía de pregrado en sociología de la Universidad del Pacífico Los únicos muertos que pueden caminar, de Rubén Darío Caicedo (2007). Por último, el trabajo de grado de Daniel Gordon, monografía de la Escuela de Comunicación Social de la Universidad del Valle, denominada La fotografía como constructora de memoria en el conflicto armado. Una experiencia de intervención social en la comunidad de Sabaletas, Valle del Cauca (2011), que hace una sistematización de la experiencia de intervención social realizada por la MappOEA, de la que Gordon participó. Fui su asesora en el proceso de evaluación que hizo con la comunidad y las conversaciones con él fueron fundamentales para comprender las consecuencias tangibles e intangibles que deja el conflicto armado en la población afectada. 


\title{
2. CONFLICTO ARMADOY MASACRES EN COLOMBIA
}

\author{
"Colombia ha vivido no sólo una guerra de combates, sino también una guerra \\ de masacres. Sin embargo, la respuesta de la sociedad no ha sido tanto el estupor \\ o el rechazo, sino la rutinización y el olvido".
}

El informe del Grupo de Memoria Histórica (GMH, de ahora en adelante) "BastaYa! Colombia: Memorias de guerra y dignidad", plantea que si se hace un compendio de las diferentes bases de datos sobre el conflicto armado colombiano (entre 1958 y 2012) puede afirmarse que en estos 55 años han muerto alrededor de 220.000 personas. De ese número, el 81,5\% corresponde a población civil, porcentaje al que para hacer más precisión sobre las dimensiones del conflicto habría que agregar el de las víctimas de la "violencia no letal", como se menciona en el documento a la acarreada por desapariciones, secuestros, desplazamiento, reclutamiento forzoso de menores y adolescentes, víctimas de violencia sexual, víctimas de minas antipersonas, entre otros (p.33). En unos y en otros, las cifras son, por lo general, inexactas, bien sea porque los criterios de inclusión de los casos pueden variar dependiendo de la organización que los recopile o porque no todos han sido registrados ${ }^{2}$.

El incremento acelerado de asesinatos se inicia a partir de 1982, cuando se intensifica el "desafío al orden guerrillero" por parte de los grupos paramilitares y se extiende la influencia del narcotráfico en el conflicto (GMH, 2013, p. 33). La acometida sistemática de masacres se convierte en una estrategia de guerra de primer orden dirigida especialmente hacia la población civil, cuyo nivel más crítico se alcanzó entre los años 1996 y 2002.Y si bien han sido cometidas por los diferentes grupos armados, fueron los paramilitares los que más recurrieron a esta práctica para imponer su presencia en toda la geografía nacional.

El uso sistemático de las masacres da cuenta de las transformaciones más significativas de la guerra desde mediados del siglo XX. Como lo explica Sthatis N. Kalyvas (2001), el paso de confrontaciones armadas convencionales de orden internacional ha sido remplazado progresivamente por el incremento de confrontaciones armadas en el interior de muy diversos países. La denominación y características de estas guerras son diversas: nuevas guerras, conflictos armados internos, guerras civiles, guerras étnicas, guerras de baja intensidad, entre otros. No obstante, más allá de las particularidades de cada conflicto, el denominador común es el incremento de víctimas en la población civil, muy por encima de la cifra entre los grupos armados en confrontación. Se trata, de acuerdo a Kalyvas, de un tipo de guerra de "carácter triangular", en tanto involucra no solamente a dos actores armados (o más) en confrontación sino también a la población civil, cuya participación en el curso de la confrontación armada es decisiva. 
Pero, ¿qué debe entenderse como masacre? El término ha recibido una serie extensa de definiciones. No es una noción que haga parte exclusiva del itinerario de guerra colombiano. Tampoco es un término que esté contenido en el corpus jurídico del derecho internacional - específicamente el Derecho Internacional de los Derechos Humanos (DDHH) y el Derecho Internacional Humanitario (DIH)- como sí están contemplados otros como genocidio, tortura, desaparición forzada de personas, asesinato, entre otros, todos ellos descritos ya sea como crímenes de guerra y crímenes de lesa humanidad ${ }^{3}$. Sin embargo, desde la sistematización de distintas experiencias, se han precisado algunas características básicas para que un determinado acto violento sea denominado de esta manera. Primero, se trata de un asesinato colectivo - que en el caso colombiano se considera mínimo de cuatro personas- pero que en otros contextos puede ser de algunas más. Segundo, se comete hacia personas indefensas o en relativa indefensión (que se escudan con armas de poco alcance, como piedras o machetes). Tercero, los asesinatos colectivos se realizan en condiciones de tiempo y de lugar que permitan unificarlos como parte de un mismo operativo; estas condiciones deben entenderse en un sentido relativamente amplio, en tanto pueden ocurrir en el transcurso de unos minutos, horas e incluso días, y en un ámbito espacial que puede ir desde un lugar cerrado (un colegio, un bar, una casa), hasta una cuadra, un barrio, una vereda o una zona geográfica de mayor cobertura regional. En cuarto lugar, los asesinatos pueden ser cometidos por una sola persona o por un grupo organizado con motivaciones de muy diversa índole. Por último, puede ser de carácter selectivo o indiscriminado ${ }^{4}$.

Al lado de esta caracterización que bien podría entenderse como de índole técnica, es necesario tener en cuenta las motivaciones específicas que en una confrontación armada impulsan el uso de esta estrategia con el propósito no sólo de asesinar a un determinado grupo en condiciones de indefensión sino de generar terror y temor, dejando un mensaje de castigo y amenaza para los sobrevivientes y testigos. A su vez, esa generación de terror y miedo está vinculada a los modos como se ejecutan estos eventos violentos, en tanto no se trata solamente de asesinar, sino de hacerlo a partir de una serie de rituales que degradan la dignidad del cuerpo asesinado y de quienes se ven obligados a observarlo. Rituales que han sido previamente planificados, que no son fortuitos, ni inusuales, ni aleatorios. Rituales que se repiten a lo largo de la historia y de la geografía universal y que permiten entenderlos como una práctica social que, como tal, media las relaciones sociales en un determinado contexto - específicamente las relaciones de poder- y contribuye a la construcción de identidades propias y del otro (Feierstein, 2007).

En el largo historial de la violencia en Colombia es posible identificar dos periodos en los que la noción de masacre con características similares a las ya expuestas ha aparecido de manera recurrente. En primer lugar, en el periodo de la Violencia, entre 1945 y 1952, sobre el que la historiadora Maria Victoria Uribe explica cómo acudir a esas formas extremas de asesinato colectivo permitía marcar diferencias entre víctimas y victimarios: estos últimos justificaban su tarea como una manera de eliminar la maldad - la del otro, la víctima- y, a su vez, de no reconocerla en sus propios actos: 
matar - de un tiro, contramatar - con la decapitación- y rematar - con cortes postmorten similares a los de la carnicería de ganado-, son maneras de eliminar cualquier rasgo de humanidad en el otro y, por ende, de facilitar al victimario su trabajo. La autora describió a las masacres de ese periodo como "actos rituales llevados a cabo al margen de las actividades cotidianas, de manera repetitiva y con una secuencia de acciones que tiene un determinado orden. No son actores casuales ni fortuitos: son acontecimientos intermitentes por medio de los cuales ciertos sectores rurales, alejados del ejercicio del poder, ejercen una forma extrema de poder" (1975).

El segundo periodo ocurre a partir de los años 80 y empieza a decrecer a partir del año 2003, cuando inicia el proceso de desmovilización de grupos paramilitares. En estas masacres, al igual que en las de la época de la Violencia, no bastaba con eliminar al enemigo, sino que, además, se pretendía generar terror en la población. Guardando estrecha relación con las masacres, el asesinato selectivo se ha constituido, por su parte, en la modalidad de violencia utilizada por los grupos armados que más víctimas fatales ha dejado: un total de 150.000 personas. Difiere de la masacre en lo relativo a su mayor individualización de las víctimas (máximo tres asesinatos simultáneos). Pero coincide prácticamente en lo demás: "los asesinatos selectivos son la expresión de una estrategia criminal que busca enmascarar las dimensiones de las acciones de la violencia contra la población civil. Esto se debe a que su carácter de acción individual y su patrón de ataque dificultan la identificación de los perpetradores. La estrategia se complementa con un régimen de terror diseñado para silenciar a las víctimas y garantizar así la impunidad del crimen" (GMH, 2013, p.43).

Más allá de las transformaciones que en el caso colombiano se han dado respecto a la definición del término masacre, éste no pierde su doloroso componente de crueldad ni el resultante trauma psicosocial, cultural y moral que acarrea en la población víctima del mismo. Tampoco se trata de un evento aislado. Por el contrario, sucede en estrecha simultaneidad con otras manifestaciones de la violencia infringida por los grupos armados, como las amenazas, desapariciones, violencia sexual y desplazamiento forzado.

\subsection{SABALETAS: CONFLICTOS Y POBLACIÓN CIVIL}

Los eventos sucedidos en la comunidad de Sabaletas se constituyen en un ejemplo sobre los modos como en contextos rurales con deficiente presencia estatal se combinan diversas formas de convivencia y de resolución de conflictos a través de -por lo menos- tres órdenes: legal/ institucional, vinculado a las instancias y procedimientos estatales de administración de justicia; tradicional e informal, asociado con las formas organizativas y culturales propias de cada comunidad; e ilegal, cuando las diferencias o desórdenes de miembros de la comunidad son dirimidos a través de la violencia física por actores armados ilegales, como narcotraficantes, grupos delincuenciales, subversivos o paramilitares, entre otros. Estas formas de administración de justicia y resolución de conflictos dan cuenta de un "pluralismo jurídico", definido por Souza Santos como aquel que "presupone que 
en el mismo espacio geopolítico (...) hay más de un derecho u orden jurídico" (citado por Espinoza, 2009, p.141). En el caso de la comunidad de Sabaletas, si bien el orden legal/ institucional ha tenido presencia permanente, ésta ha sido débil y ha convivido con diferentes manifestaciones de los otros órdenes descritos (tradicional e ilegal). Puede hablarse en este caso de cuatro etapas que transformaron progresivamente la vida social, económica y cultural de la región.

\subsubsection{Primera etapa: Primacía de la justicia comunitaria.}

Hasta principios de los años 80, la comunidad de Sabaletas se dedicaba principalmente al cultivo y venta del borojó y del chontaduro. No había presencia del narcotráfico ni de grupos subversivos, de modo que se vivía en una relativa tranquilidad. Fue un periodo en el que se presentaban simultáneamente dos formas de administración de justicia y de resolución de conflictos: los construidos por el Estado, a través de la inspección de la policía, y de manera mucho más acentuada la justicia tradicional, impartida por las formas organizativas de la propia comunidad en las que era fundamental la presencia y legitimidad de algunos ancianos de la zona (Gordon, 2012, p.18). Así mismo, se acudía al acatamiento de una serie de pactos informales sobre los que no era necesaria la intervención de un tercero - por ejemplo los organismos estatales-. Este tipo de normatividad, correspondiente a los lazos sociales de la propia comunidad, se entiende como la justicia comunitaria o justicia popular, de acuerdo a la definición que de la misma hace Merry (2003): “... es un proceso relativamente informal en cuanto al ritual y al decoro utilizados, no profesional en el lenguaje y personal empleados, local en el alcance y limitado en la jurisdicción, para adoptar decisiones y hacer obligatorio el cumplimiento de una serie de normas.” (p.41). En el caso de Sabaletas, el paso hacia la utilización del componente institucional - acceso a jueces, por ejemplo- o de la coerción - inspección de policía y cárcel- sólo se hacía cuando la justicia comunitaria no era suficiente para dirimir una falta o un conflicto.

\subsubsection{Segunda etapa: Primacía de la coerción ilegal}

En este segundo momento, el narcotráfico y el turismo afectaron significativamente la vida comunitaria y económica de Sabaletas y otras veredas cercanas (Guzmán y Moreno, 2007). En primer lugar, la presencia de grupos de narcotraficantes - primero del Cartel de Cali y después del Cartel del Norte del Valle- que compraron lotes para la recreación particular y para la construcción de corredores estratégicos para el tráfico de drogas, se constituyó en una nueva fuente de trabajo e impuso la presencia cotidiana de armas de fuego y la circulación de altas cantidades de dinero (Gordon, 2011, p.17; Caicedo, 2007, p.29). En segundo lugar, el surgimiento de un desmedido y no planificado turismo conllevó a un cambio drástico en las actividades económicas y culturales, aunado a la creciente presencia de comerciantes de otras regiones del país - llamados genéricamente como "paisas"-. La delincuencia común también empezó a tomar fuerza en la región, lo que implicó para la comunidad la búsqueda más frecuente de la justicia estatal, que actuó de manera ineficiente frente a los nuevos problemas.

De ahí al uso de la coerción ilegal sólo había un paso: en 1993 se presentó el primer 
caso de "ajusticiamiento" (asesinato) a un delincuente por parte, al parecer, de miembros de la misma comunidad: ni la justicia comunitaria ni la justicia estatal pudieron contener la infracción de la norma, que fue resuelta a través de "la justicia por mano propia".

\subsubsection{Tercera etapa: Primacía de la justicia guerrillera.}

Con la captura de los capos del cartel de Cali en 1996, se generó una reorganización del negocio del narcotráfico en el Valle del Cauca, en el que empezaron a figurar los nuevos líderes del cartel del norte del Valle y con los que se facilitó la entrada de las FARC al negocio del narcotráfico en la zona. A partir de entonces - y en connivencia con los grupos de narcotraficantes- las FARC toman un papel protagónico en las formas organizativas de la comunidad y en sus mecanismos de resolución de conflictos. La guerrilla se constituyó en un contrapoder frente al poder estatal, al cual la comunidad acudía para dirimir los conflictos. Todo ello, más la serie de impuestos que cobraban, y las amenazas y asesinatos de quienes consideraban eran informantes del ejército, conllevó a una vida comunitaria marcada por el miedo y la estigmatización por parte de las fuerzas estatales (Caicedo, 2007, p.50).

Una de las primeras formas como las FARC empiezan a tomar el poder en la población es a través del uso de la justicia expedicionaria, descrita por Mario Aguilera (2014) como aquella en la que se apela al ajusticiamiento o pena de muerte a delincuentes que afectan la vida de la región "acusados de delitos menores y de bandas organizadas denunciadas por homicidios, atracos, violaciones sexuales y robos" (p.243). De hecho, en 1995 las FARC realizan la primera masacre contra cinco jóvenes que eran reconocidos por formar una banda delincuencial; como también lo expresa Aguilera a propósito de la justicia expedicionaria, este hecho generó una cierta aprobación por parte de la comunidad, en tanto así se resolvía un problema que los venía afectando y frente al cual el Estado y su aparato coercitivo legal no habían respondido: La masacre primera que hubo acá ocurrió porque unos muchachos se habían dedicado a vender bazuco y a robar aquí en Sabaletas, $y$ dicen algunos que la guerrilla vino y advirtió que calmaran la situación, ellos hicieron caso omiso, entonces luego pasó la guerrilla y dejó cinco muertos (Testimonio de un poblador. Gordon, 2011, p.19).

De otra parte, con la promulgación de la ley 70 de 1993 que reconoce legalmente el territorio de los afrocolombianos, miembros de la comunidad de Sabaletas iniciaron un proceso organizativo para beneficiarse con la ley. En el año 2000 el Estado reconoció a Sabaletas como Consejo Comunitario y le otorgó a su junta directiva autonomía sobre el territorio colectivo, un mandato legal que lo convierte en el máximo ente de gobierno interno, y por ende, competente para la toma de decisiones en todo lo relacionado con la administración del territorio y sus recursos naturales. Este proceso de titulación colectiva llevó a Sabaletas a una nueva etapa en la que intentó afrontar el conflicto 
y subsanar el deterioro de su tejido social, asesorándose y dándose a conocer por medio de las organizaciones civiles y ONG's (Caicedo, 2007, p.70; Gordon, 2011, p.22).

Paradójicamente pues, en medio del conflicto armado, la población civil de Sabaletas accede a formas organizativas propias de la administración de justicia institucional.

Podríamos decir que la ya débil justicia comunitaria encuentra un sustituto en formas organizativas exigidas por entes externos, ya sea de orden estatal o no estatal e internacional, como el caso de ONG'S que llegan a la región a realizar procesos de intervención social para la recuperación de las comunidades frente al conflicto armado.

\subsubsection{Cuarta etapa: Primacía de la justicia de los paramilitares}

Cuando en 1998 el Frente Calima de las Autodefensas Unidas de Colombia AUC ingresa a la costa pacífica del Valle del Cauca, el sector de Sabaletas entra a constituirse en una zona en disputa entre los grupos insurgentes y los paramilitares, todo ello teniendo en medio a la población civil. A partir de ese momento, progresivamente las AUC se toman el control de la zona aplicando la modalidad de justicia que los ha caracterizado, las masacres a la población civil, específicamente personas que eran denunciadas como colaboradores de la guerrilla o como milicianos. De acuerdo a la base de datos del GMH, entre los años 2000 y 2005 se presentaron en Buenaventura y sus 19 corregimientos 22 masacres. De este periodo se trata este análisis.

\section{MASACRES Y TRATAMIENTO MEDIÁTICO}

"Esperemos a que haya un muerto", fue lo que me contestaron en Bogotá cuando conté que había una amenaza de masacre. Uno se queda mudo; cuelga el teléfono y se pregunta: ¿Qué está pasando aqui? ¿Será que los valores cambiaron? Ramón Eduardo Martínez, corresponsal de televisión de Cúcuta ${ }^{5}$.

La Gabarra es un corregimiento del municipio de Tibú, Norte de Santander, que ha sido durante varias décadas objeto del dominio guerrillero (ELN y FARC) y de la agresión paramilitar. Durante los meses de mayo a agosto de 1999 grupos paramilitares dirigidos por Salvatore Mancuso realizaron tres operativos que dejaron un total de 123 personas asesinadas: el 29 de mayo, el 31 de julio y el 21 de agosto. A la última de ellas hace referencia el periodista cucuteño, quien narra además cómo siendo corresponsal de Noticias RCN una vez reportó el asesinato de las primeras siete personas desde la sede central le respondieron: "Eso sí es noticia, vaya cúbrala". Lo que primó en este caso fue, pues, el criterio de magnitud para darle paso a la noticia; en cambio, el criterio convencional de proximidad se constituyó en un obstáculo para que desde la dirección del medio en Bogotá se prestara mayor atención a la situación de esa lejana población. Y no es, en absoluto, un caso aislado.

De hecho, no fue sino hasta que iniciaron las audiencias con paramilitares desmovilizados en el contexto de la Ley de Justicia y Paz en el año 2005 y con la constitución de la Comisión Nacional de Reparación y Reconciliación (CNRR) que 
empezaron a aparecer de manera más recurrente los relatos de víctimas y victimarios sobre las historias de violencia sucedidas en estas diferentes regiones del país. Hasta ese momento, en el imaginario de muchos colombianos, muy probablemente la Masacre de las Bananeras Ciénaga, departamento de Magdalena, diciembre de 1928- seguía siendo el referente de primera mano. En adelante, las masacres que recibieron mayor destello mediático fueron aquellas en las que la cantidad de víctimas superaba con creces el número mínimo de cuatro personas, algunas de las cuales han sido documentadas en los diferentes informes del Grupo de Memoria Histórica: El Salado, Trujillo, Bojayá, Segovia y la Rochela, entre otros.

En esa cotidianización de las masacres en el país, es evidente el papel jugado por los medios masivos de comunicación. Una cotidianización que desde el punto de vista mediático podría señalarse más bien como invisibilización, ocultamiento y desinformación. Invisibilización, en tanto su aparición en la agenda mediática durante las dos últimas décadas se ha caracterizado por su insuficiente y fragmentado posicionamiento como tema de importancia nacional; ocultamiento, en tanto muy a pesar de que muchas masacres eran anunciadas, las lógicas del silencio y del miedo que se imponen en los escenarios regionales impidieron la posibilidad de su denuncia pública, a lo que se sumaron las lógicas de noticiabilidad de las grandes empresas informativas; desinformación, porque abundan las impresiones en el uso de términos (es común el uso indiscriminado de palabras como asesinato, matanza, masacre y genocidio, entre otros), en la ubicación geográfica de la zonas afectadas, en la cantidad de víctimas (mortales, sobrevivientes y desplazados), en los autores materiales e intelectuales y ni qué decir del contexto que las motiva (territorial, económico, político, etc.). A propósito del cubrimiento de estos eventos, el periodista televisivo José Gregorio Pérez, que entre 1997 y 2002 trabajaba en el noticiero CM\&I comenta:
"No se visibilizaba directamente, si había un eco, pero no es la dimensión que ha demostrado el proceso de Justicia y Paz, toda esta rendición de esta gente y todo eso que Memoria Histórica ha venido recuperando. Uno como periodista lo vivía, había el eco en el momento pero no más. Por ejemplo, yo no vi en la época despliegue mediático grande para la masacre de El Salado, también porque esta gente (los paramilitares) empezó, yo no digo a cooptar, pero sí a amenazar, a molestar y mandar mensajes y llegó un momento en que eso se volvió también una manera de la prensa de mirar a ver si podía o no podía informar"6.

La falta de posicionamiento sistemático de estas tragedias y su tratamiento fragmentado, pueden explicarse por varias razones. Una decisiva es el hecho de que el incremento de acciones en contra de la población civil desde mediados de los años 90, afectó considerablemente el ejercicio del periodismo y en consecuencia el aumento de violaciones a la libertad de expresión: entre 1996 y 2005 hubo 61 periodistas asesinados (FLIP: 2012). De hecho, a raíz del incremento de estos actos violentos se crearon organizaciones periodísticas no gubernamentales que brindaron apoyo a los periodistas, especialmente de las regiones más apartadas del país: Medios para la Paz (1998), la Red de Alerta y Protección al Periodista de la Fundación para la Libertad de Prensa (1999) y el Proyecto Antonio Nariño (2001), cuyos objetivos se centraron sinérgicamente en un proceso de protección, denuncia, acompañamiento y capacitación a los periodistas encargados de cubrir el conflicto armado colombiano. De otra parte, a raíz de la gestión de estas organizaciones se creó en el año 2000 El Programa de Protección a Periodistas y Comunicadores Sociales del Ministerio del Interior y de Justicia (Alzate, 2010, p.91). 
Al lado de estas razones de suficiente peso, el sistema político- gubernamental del Estado colombiano se encontraba debilitado e inestable a raíz de otros eventos que terminaban por copar la agenda de los medios de comunicación: actos terroristas y persecución al cartel de Medellín (gobierno Gaviria), denuncias de ingreso de dineros del Cartel de Cali a la campaña del presidente Ernesto Samper Pizano e inicio del Proceso 8.000 (gobierno de Samper), diálogos del Caguán y su posterior ruptura (gobierno Pastrana). Aunado a lo anterior, deben tenerse en cuenta las reconfiguraciones sucesivas del narcotráfico a raíz de la muerte de Pablo Escobar, la posterior captura de los integrantes del Cartel de Cali, el incremento de las tomas guerrilleras y del secuestro de civiles y militares por parte de las FARC. Como plantea el mismo informe del GMH respecto a las masacres, solamente aquellas que se caracterizaron por el alto número de víctimas y por grandes crisis humanitarias contaron con una mayor visibilización en los medios de comunicación (2013, p.45).

\subsection{Criterios de selección}

La pregunta de partida de la que surgió este análisis fue la siguiente: ¿Desde qué lugar puede cubrirse con mayor calidad informativa una coyuntura vinculada al conflicto armado como una masacre? ¿Hay un lugar más idóneo que otro para hacerlo? Con lugar me refiero a la ubicación del medio de comunicación en el campo mediático y a su ubicación geográfica. Respecto al campo mediático, seleccioné tres medios de comunicación impresa de larga tradición, lo que supone que, en medio de los avatares económicos del periodismo, han logrado una sostenibilidad económica y, en consecuencia, tienen una historia en su política editorial. Respecto al lugar geográfico, interesaba analizar los efectos de la mayor o menor proximidad al lugar de los eventos en el tipo de información publicada.

La selección de los medios se hizo sin conocer previamente el tipo de trabajo periodístico que habían realizado sobre las masacres seleccionadas. En el contexto nacional el diario seleccionado fue ElTiempo, teniendo en cuenta que durante el periodo analizado el otro periódico nacional, El Espectador, era semanario (desde el 2001 hasta el 2008). En el contexto regional, seleccioné el único medio impreso que puede denominarse como tal en el contexto del Valle del Cauca, el diario El País. En el contexto local, escogí el periódico El Puerto, por considerar que era el de mayor tradición en el municipio de Buenaventura (76 años) y por la ausencia en la época de otros medios impresos de orden local (en el 2012 surgen las versiones bonaverenses de los periódicos de crónica judicial Extra y de Q'hubo, ésta última ligada al Diario El País S.A.). 
Sobre El Puerto, podemos decir de antemano que no publicó nada. La explicación dada por su director, Diego Calero, fue que el énfasis del periódico ha sido el económico y el político, lo que en términos de fuentes de información focaliza su interés en la Sociedad Portuaria y en la Alcaldía municipal:

"Si usted me pone en esa línea concreta, digamos que es la parte económica; es decir, si hay cómo ubicarlo; y de pronto en igualdad o seguido estaría la parte política. ¿La parte económica por qué? Porque como yo estoy tan marcado por la actividad portuaria, a mí me parece injusto que un puerto o un terminal de tanta competencia, de tanta movilidad, de tanta generación económica para el país, no tenga un espacio informativo que marque la ciudad; y la realidad es que a la ciudad no le interesa la actividad portuaria; le interesa qué puede sacar de la actividad portuaria, pero no le interesa noticias de la actividad portuaria; al interior del país sí. Y lo otro es la Alcaldía, administración municipal. Esas son las dos líneas; la tercera eventos ¿no? Sucesos; pero básicamente es eso"7.

Debe tenerse en cuenta que como sucede con la gran mayoría de los medios regionales, El Puerto no ha contado con estabilidad económica y su principal fuente de financiamiento es la pauta publicitaria, que se centra en las mismas fuentes de información que prioriza. Fundado en los años 30 por Teodomiro Calero, el padre del actual director de la publicación, El Puerto fue durante varias décadas, un referente informativo y cultural de Buenaventura. Con la enfermedad y posterior muerte de Teodomiro, el periódico empezó a contar con varios directores, hasta que su hijo, Diego Calero, un ingeniero industrial dedicado al tema de los puertos marítimos, optó por tomar la dirección desde 1987. Eso explica el giro editorial del impreso y el poco énfasis en temas vinculados a la violencia que desde los años 80 empieza a azotar a la región. A su vez, el tema de la seguridad personal se constituye en una razón definitiva para no tocar esta clase de temas:

“... Un ejemplo, tú de pronto lo has observado, que hoy las fotos y los videos de las personas que están alineadas para reconocimientos, recién capturados, los hace la misma policía, porque ya los medios dejaron de ir a hacer esa vuelta; ni a tomarle fotos a esos señores ni a hacerles videos; ya la misma fuerza pública hace su trabajo para que salgan en los medios oficiales de ellos ¿por qué? Los capturan, el juez de garantías los libera y después queda el periodista con eso. Entonces no, se acabó esa vuelta. Entonces son cosas que han ido evolucionando por marcha del oficio"

- Por la seguridad personal.

"Sí, sí; pero ha sido en todo el país que esa generalidad se da. Pero en eso no nos metemos. Más bien aquí el vacío que hay es la falta de ingenio". 
No obstante, el criterio de invisibilización de los temas vinculados al conflicto armado, la voz de este periodista termina siendo testigo de cómo afectó el conflicto armado en Buenaventura a la ciudad y su zona rural. A propósito de la guerrilla dice: A mí me llevaron y me cuestionaron: ¿usted por qué no publica? Les dije: "porque ustedes no mandan información y yo no la voy a venir a buscar, porque ustedes se mueven mucho; yo soy de pavimento, yo no soy de monte. Ah, pero si nosotros le mandamos isi? Pues manden y yo miro a ver qué; porque hay muchas cosas de las que uno publica que ustedes también han publicado; o sea, estamos hablando de lo mismo, lo que pasa es que ustedes son más radicales, y yo necesito es vender, no imponer".

\subsection{Criterios de análisis}

De acuerdo a Miquel Rodríguez Alsina (1996) en el proceso de construcción de la agenda informativa en los medios de comunicación intervienen al menos tres grados de selección y organización de la información. El primer grado se refiere a la regulación de un genérico derecho de acceso o derecho de entrar en el circuito informativo; es decir, de acuerdo a los criterios de noticiabilidad el medio define si un determinado evento será o no publicado.

En caso de que la respuesta sea positiva, se pasa al segundo grado de selección y organización de información, denominado por el autor como función de jerarquización. De acuerdo a ello, se atribuye una mayor o menor importancia de los acontecimientos y de acuerdo a ésta se determina el lugar que va a ocupar dentro del conjunto de los eventos informativos; se trata de responder entonces a preguntas como la siguientes - en el caso de los medios impresos - (a los que se refiere este trabajo): ¿El evento merece aparecer en la primera página del periódico? Si es así, ¿en qué lugar de la página? Si no, ¿a qué sección se envía? ¿Qué extensión amerita el tema? ¿Requiere o no la presencia de fotografías? ¿Se hace reportería gráfica o basta con acudir a material de archivo? Etc.
De manera simultánea a estas preguntas y decisiones se pasa al tercer grado de selección, llamado por Alsina como función de tematización, con la que se procede a una nueva organización del evento de acuerdo a la cual se pretende concentrar la atención pública y la interpretación de la información en un marco: ¿Es un evento de carácter regional, local o nacional? ¿Puede ubicarse en secciones como Unidad de Paz, Judiciales, Orden Público? Se pasa también a la estructuración de la información, en la que se presenta una jerarquización en lo relativo a las fuentes, actores, escenarios y testimonios utilizados.

El análisis sobre las dos masacres seleccionadas se realizará principalmente a partir de los anteriores criterios. Es decir, en primer lugar se tendrán en cuenta los distintos grados de selección de información - derecho de acceso (1o. Grado), función de jerarquización $\left(2^{\circ}\right.$. Grado) y función de tematización ( $3^{\circ}$. Grado). En segundo lugar se analizará la presencia de fuentes de información y su función en el conjunto de la información; estas fuentes se clasificarán en: Fuentes oficiales/Fuentes privadas/Expertos/Fuentes ciudadanas- víctimas/ Fuentes ciudadanastestigos/ Fuentes ciudadanas- reivindicadores. Al lado de estos dos ejes gruesos se revisarán los siguientes elementos: contexto de las masacres (geográfico, político, militar, humanitario, etc.)/ Antecedentes/Consecuencias/Caracterización de actores.

\subsection{Masacre del 10 de mayo del año 2000}

La primera masacre de las AUC en Sabaletas tuvo lugar el 10 de Mayo de 2000 en horas de la madrugada. Hombres uniformados llegaron a la población y comenzaron a buscar a la gente en sus casas para dirigirlas a la plaza principal. Niños, mujeres y hombres conformaron una rueda en la que se encontraban los hombres armados y un encapuchado, quien señalaba a quienes seguidamente eran asesinados con 
cuchillos y fusiles, en medio de burlas y vulgaridades, amedrantando a los presentes e impidiéndoles que cerraran los ojos o se retiraran (Gordon, 2011, p.22; Gobernación del Valle, s.f.). Esta fue la primera masacre, con doce víctimas mortales, cometida por los paramilitares. Con ella este grupo hace su "presentación oficial" en la costa pacífica del Valle del Cauca a partir del ritual y la planificación explicada anteriormente. Dado que la masacre ocurrió en horas de la madrugada - en que los medios impresos ya están listos para circulación- esta masacre sólo pudo ser registrada el sábado 12 de mayo.

A pesar de su importancia por ser la primera cometida en el pacífico vallecaucano, el periódico nacional ElTiempo hizo una total omisión. Es decir, el primer grado de selección de información - el derecho de acceso- le fue cien por ciento negado. Por su parte, el periódico regional El País hizo un despliegue significativo, en el que el evento obtuvo primera página en la parte superior izquierda del impreso con el título "Autodefensas asesinaron a doce personas. Masacre de AUC en Buenaventura"; no obstante si bien logró un lugar estratégico, debe tenerse en cuenta que en términos gráficos tuvo mayor importancia un evento comercial, vinculado al lanzamiento de un portal web foto No.1).

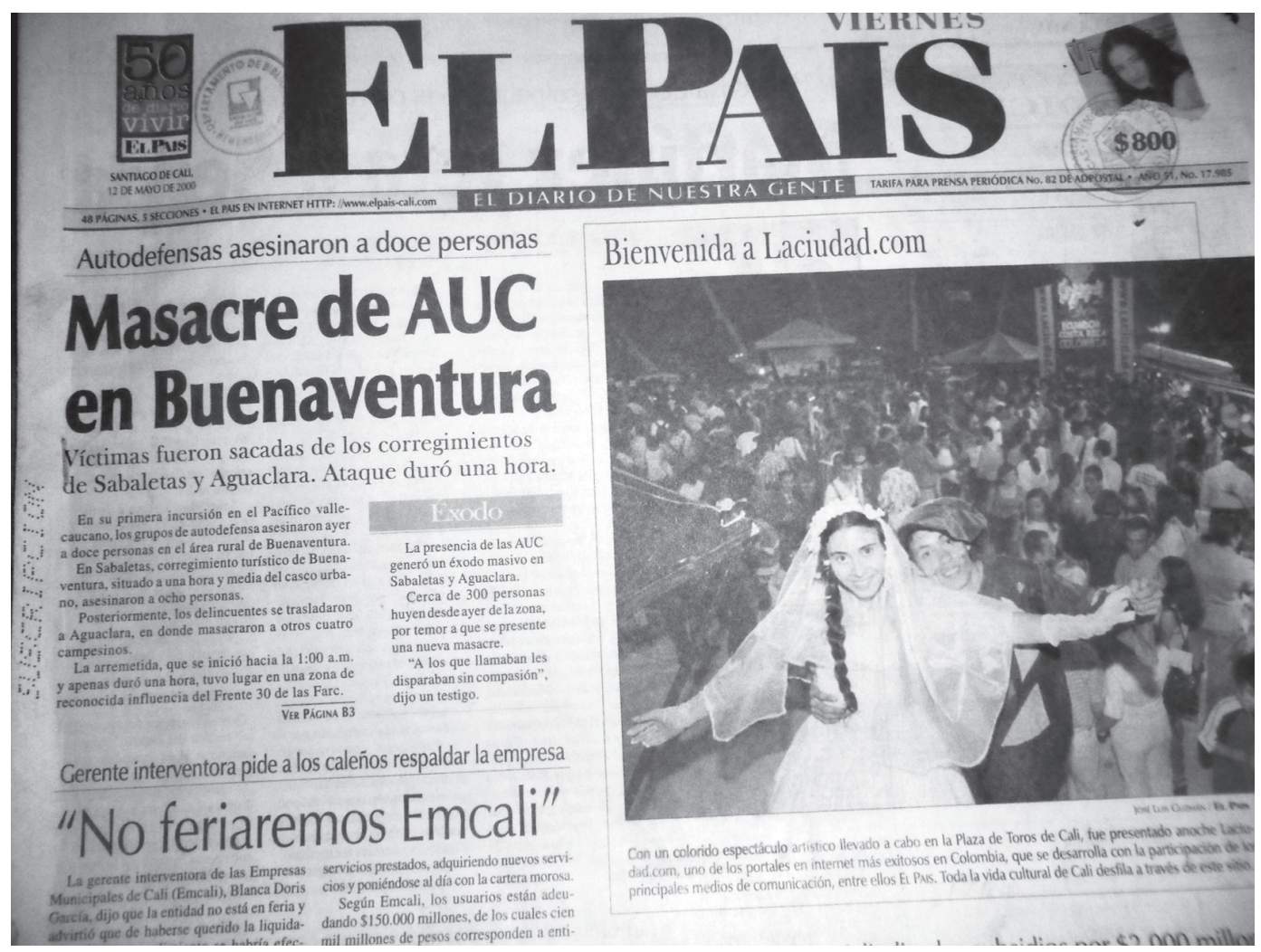

Foto No.1 
El desarrollo de la información de la primera página fue enviado a la sección La Región (página B3) en la que ocupó casi la totalidad de la página. El despliegue fue, pues, significativo ( $2^{\circ}$ Grado de selección). En lo relativo a la función de tematización ( $3^{\circ} \mathrm{Grado}$ ) se destacan que el marco interpretativo de la noticia se centra en que se trata de la primera incursión de grupos paramilitares en la costa pacífica del Valle del Cauca, lo que supone la consideración de un elemento de contexto significativo (foto No.2). En el relato periodístico incluyen los elementos fundamentales de una noticia: número y nombre de las personas asesinadas, autores, lugar y duración. El informe incluye también fotografías a color que muestran los efectos de la incursión armada de la población: los grafitis que anuncian la llegada de los nuevos actores de la zona en medio de la continuidad de la vida comunitaria (niño en bicicleta) y los efectos inmediatos del evento: desplazamiento de la población y presencia de fuerzas militares (foto del carpati). Así mismo se apela a la infografía - uso de gráficas, en este caso un mapa - para ubicar geográficamente a la población.

En lo relativo a las fuentes de información utilizadas, hay presencia importante tanto de fuentes oficiales como de fuentes ciudadanas. Respecto a las fuentes oficiales, la primera en aparecer es la de mayor autoridad municipal, la del alcalde, cuyo testimonio, sin embargo, se refiere a opiniones o testimonios repetitivos que aportan poco a la resolución de un problema: "Es una locura, a uno no le cabe en la cabeza que le hayan hecho esto a esas humildes personas" (El País, mayo 12 de 2000). Pero al lado de este testimonio la nota informativa dice que "las autoridades del Puerto se abstuvieron de suministrar información sobre estos asesinatos". No se aclara en este punto quiénes son "las autoridades del puerto”: ¿El alcalde que se lamenta de lo sucedido? ¿Las Fuerzas militares? Otra pregunta básica surge de esto: ¿Por qué no hay información oficial excepto los nombres de las personas asesinadas? De hecho, todo el relato periodístico se construye a partir de los testimonios de los testigos y las víctimas.

Respecto a este primer reporte de la masacre, debe destacarse que hay una serie de datos que pretenden responder a los elementos básicos de la información y da cuenta de dos elementos de contextos fundamentales: el énfasis en que se trata de la primera masacre de las AUC en el sector y de que se da inicio a un desplazamiento forzado por parte de la población. Sin embargo, estos dos aspectos no logran un mayor desarrollo y, en cambio, son adobados con una serie de expresiones y adjetivos que promueven la perspectiva emocional de la tragedia: "los grupos de autodefensa sembraron el dolor y muerte", "la muerte, la angustia y la incertidumbre..." o "muerte, venganza y destrucción”. 


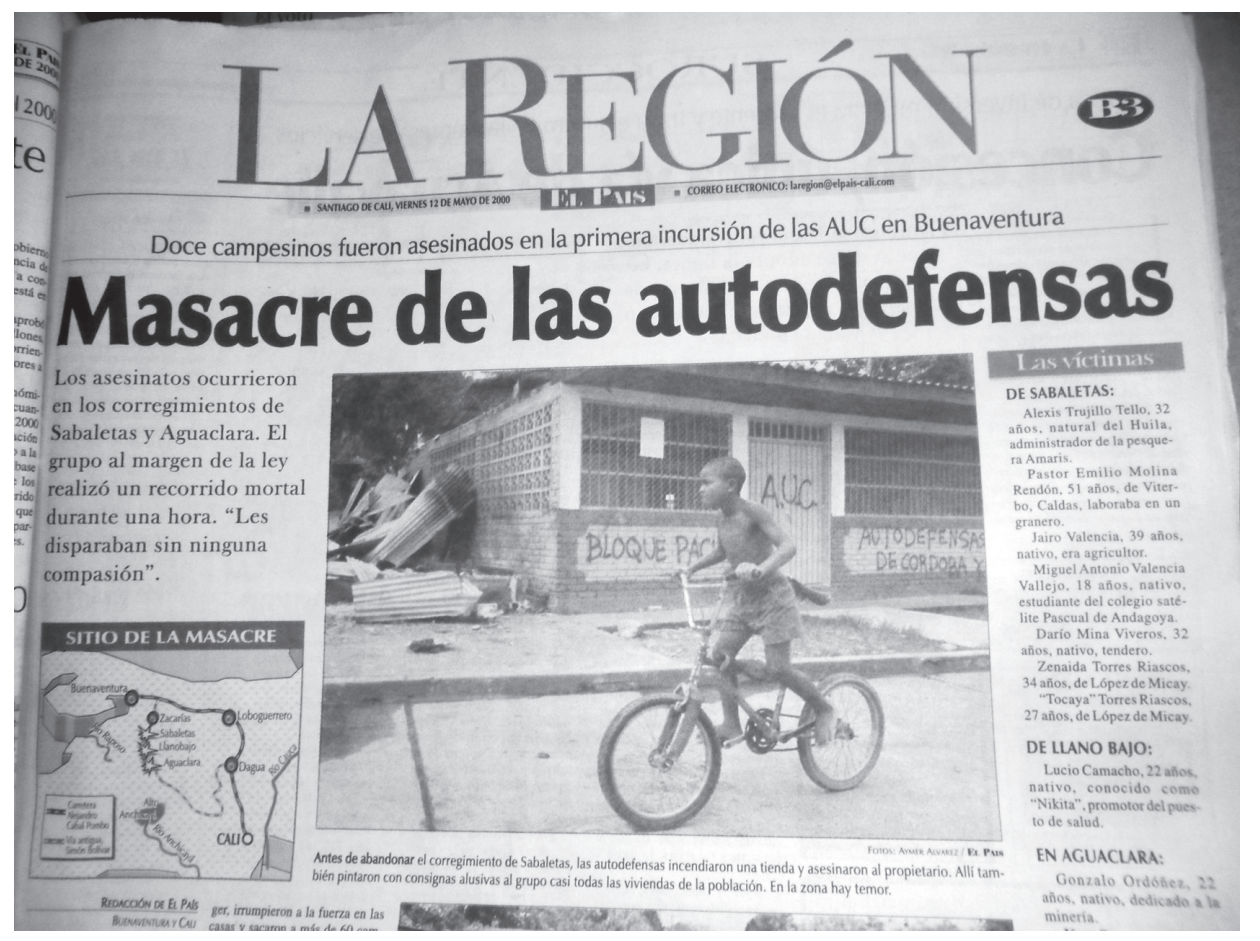

Foto No.2

Al día siguiente - 13 de mayo de 2000- aparece el tema de nuevo en primera página $\left(1^{\circ}\right.$ grado: derecho de acceso) con el título "Víctimas de la AUC serían 16”, pero con un nivel de jerarquización menor que el del día anterior - parte inferior de la página y con una mínima extensión, dos columnas de ancho y $5 \mathrm{cms}$. de alto. La noticia es remitida a página B2 sección La Región, Suroccidente- donde tiene una extensión significativa en la página, con una fotografía referida a las consecuencias de la masacre: el desplazamiento forzado (foto No.3). Respecto a la presencia de fuentes de información, en esta nota priman nuevamente las versiones de los testigos, que dan cuenta de otra masacre sucedida en la misma fecha en un corregimiento cercano a Sabaletas (vereda La Cascada), lo que suma a 16 el número de víctimas mortales; pero al lado de ellos, llama la atención el testimonio de los paramilitares que dan un "parte de guerra" reconociendo la autoría de la masacre y anunciando que capturaron a uno de los comandantes del Bloque Occidental de las FARC.

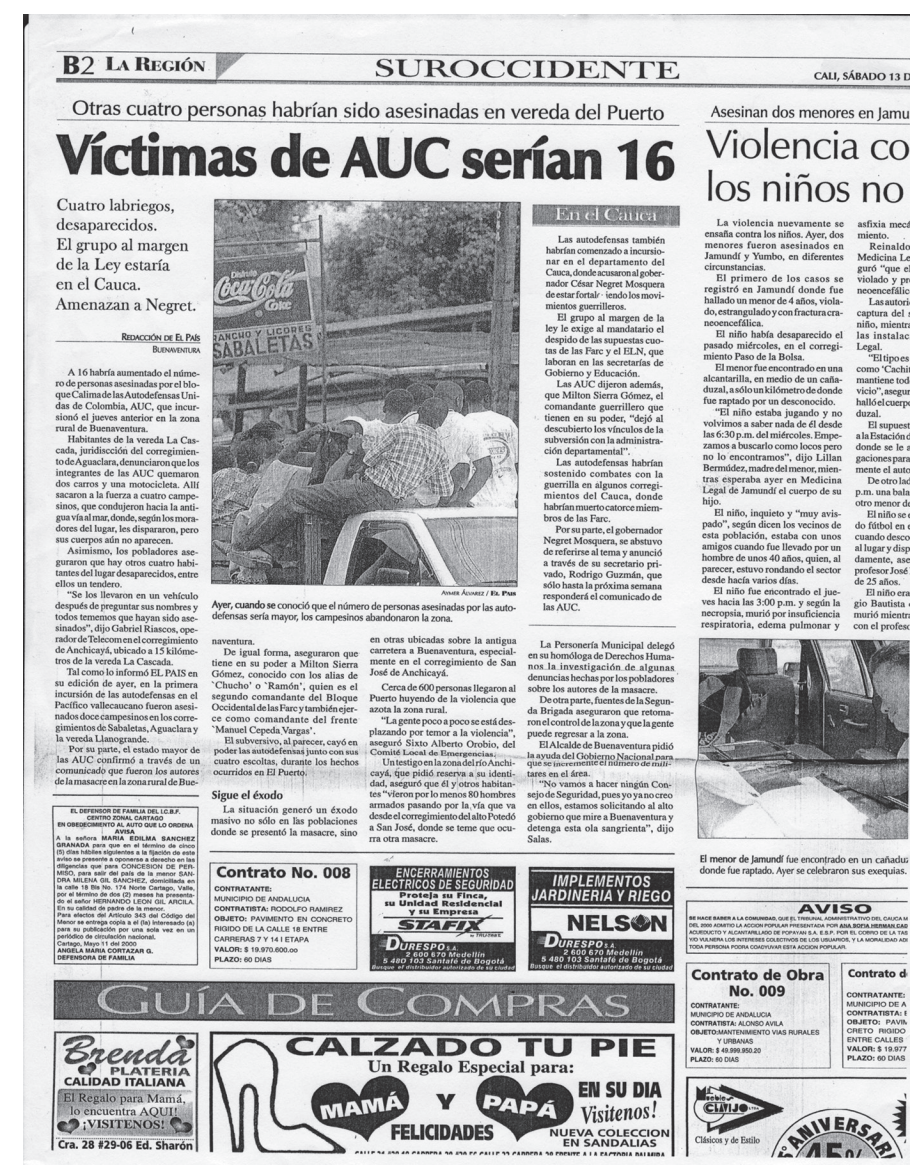

Foto No.3 
En términos de tematización ( $3^{\circ}$. grado) el énfasis se hace pues en el número de víctimas - criterio de cantidad- respecto al número de personas asesinadas y a quienes iniciaron desplazamiento forzado; la presencia de fuentes oficiales queda relegado al último párrafo del texto, en el que el alcalde de Buenaventura se refiere a la ineficacia de los Consejos de Seguridad para resolver la problemática.

Llama la atención pues el hecho de que no hay ninguna explicación oficial sobre las razones de la masacre. Todo queda en manos de los pobladores. Así mismo, el tratamiento dado al comunicado de las AUC parece un parte de guerra positivo frente a la captura de cabecillas de las FARC.

Esta primera masacre de los paramilitares muere mediáticamente el día 15 de mayo, cuando en la página de Región (ya no en titulares), aparece la nota "Desplazamiento ronda al Puerto" (foto No.4), cuya tematización se enfoca en el desplazamiento de miembros de la comunidad indígena de la vereda La Meseta a raíz de la presencia de paramilitares en la zona; también se menciona el éxodo de la comunidad afrocolombiana frente a la masacre ocurrida días antes. Sin embargo, para referirse a ella se dice:"Debido al temor generado por la incursión de la semana pasada de grupos de autodefensas en el área rural de Buenaventura". Por primera vez en el transcurso de las notas publicadas sobre la tragedia, se menciona una fuente militar al final del artículo - la Segunda Brigada de Infantería marina- para decir que ésta "mantiene el control de la carretera Simón Bolívar", que han garantizado a la comunidad la seguridad en la zona y que no se han presentado desplazamientos; en síntesis una voz oficial que defiende básicamente su función institucional. No hay respuesta sobre las razones de la masacre, sobre las víctimas, sobre las secuelas para la población (excepto el desplazamiento) ni sobre persecución o castigos para los responsables. Debe

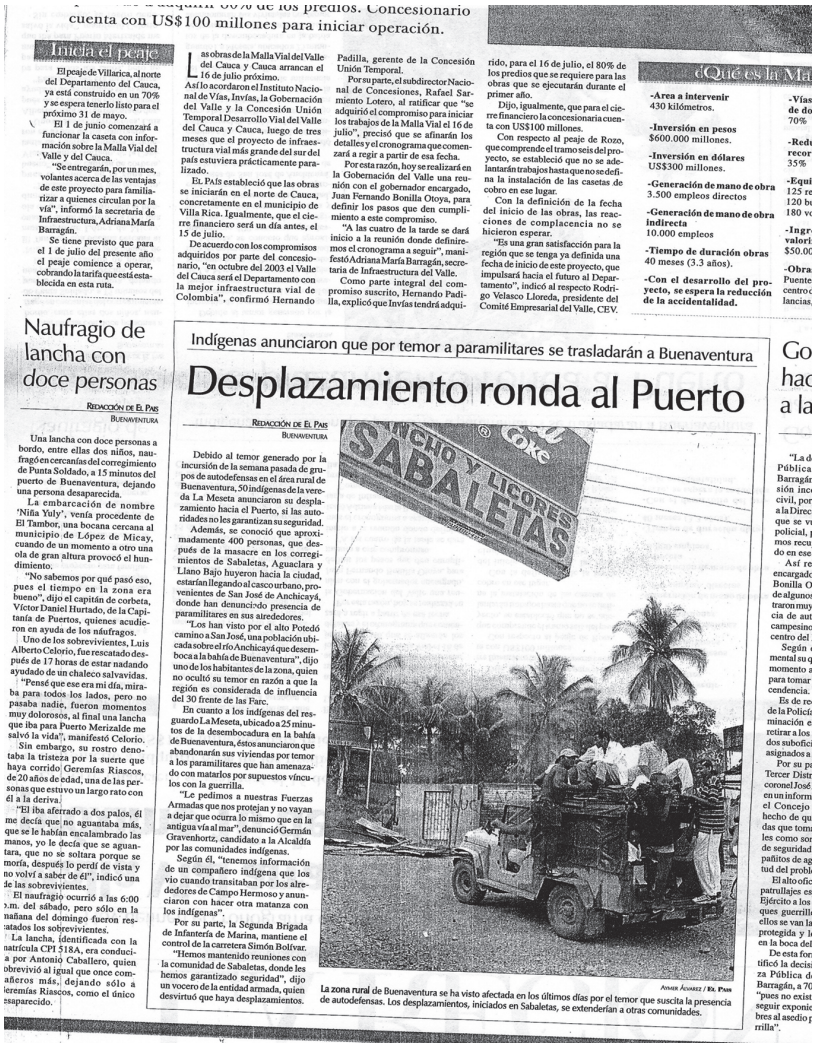

Foto No.4 tenerse en cuenta que retomando información del Cinep, el portal Verdadabierta.com afirma que antes de la masacre el Bloque Calima de las AUC pasó por retenes militares del Batallón Palacé y Farallones, ubicados en la vereda El Danubio (centro del Valle del Cauca) y que posteriormente se refugiaron en un batallón militar (http: / / rutasdelconflicto.com/interna.php?masacre=175). 


\subsection{Masacre del 14 de junio del año 2003.}

En el 2003 el bloque Calima de las AUC anunció al gobierno nacional un cese de hostilidades. Este hecho permitió desplazamientos estratégicos del grupo ilegal que arremetió de nuevo contra la comunidad de Sabaletas: "Como tendencia general, las tropas paramilitares, después de la declaración de cese de hostilidades, se retiran progresivamente de zonas como la cordillera occidental, para concentrarse más en regiones medias de la cordillera central y en la zona pacífica del departamento. Este movimiento se evidencia a raíz de la masacre que cometieron en el corregimiento de Sabaletas, en Buenaventura, el 14 de junio del año 2003" (Guzmán y Moreno, 2007, p.274). En medio de las festividades del Día del Padre, el 14 de junio de 2003 hombres armados aprovecharon una reunión en una de las casetas ubicadas al lado del río para disparar indiscriminadamente contra todas las personas que se encontraban bailando:

Había una celebración, una fiesta en una casa, como a mí esas cosas no me gustan no fui. Estábamos en la casa, eran las 11:00 de la noche, primero pasó una moto, de ahí pasó un carpati y atrás pasó otro. Cuando yo me asomé hacia la carretera, se fueron bajando armados, entonces yo como estaba con mi familia, mis nietos y mi hermana, me pasé al frente donde mi sobrina y les dije: Tírense al monte que nos vienen a matar. Cuando oímos fue la ráfaga. Paratata bum bum bum, Dios mío nos van a matar. La hija mía que andaba con mi otra sobrina, la que cayó en la masacre, andaban bailando; ella se tiró al río y por aquí le quiso pasar una bala, y como acá en la casa estaba la hija, el marido se fue a ver qué pasaba y de una lo mataron, de allá del puente le pegaron derechito al corazón, dejó seis hijos pequeños. De allí se vinieron a tocar puertas, mi compadre Silvano como estaba borracho le dijeron que se entrara y no se quiso entrar, ahí lo cogieron y le dieron un tiro en la cabeza. Otro primo que se llamaba Julio lo degollaron, le pegaron un solo machetazo. Como la mujer de mi cuñado no pudo cerrar la puerta, entraron ahí, estaba dormido, le pegaron un tiro en la sien, se le llevaron la grabadora, se le llevaron los CD, el televisor y se fueron. Gritaban: por fin les dimos, por fin les dimos, todos estaban borrachos (Testimonio de un poblador. Gordon, 2011, p.23)

Si la masacre del 10 de mayo del 2000 fue el saludo de llegada de las AUC a la comunidad de Sabaletas, la del 14 de junio de 2003 puede ser considerada como una primera despedida frente al proceso de desmovilización que esta agrupación iniciaba. En esta ocasión, el periódico El País anunció la tragedia el lunes 16 de junio como "Masacradas seis personas en zona rural de Buenaventura" con gran despliegue en la página B4, sección Valle del Cauca, y la inscribió dentro del marco temático de "Orden público" (foto No.5); en esta ocasión no tuvo ninguna mención en la primera página.

Curiosamente, para ilustrar este hecho se toma una fotografía de archivo que había sido utilizada - con un grado de acercamiento diferente, pero desde el mismo ángulo- para ilustrar la masacre del 10 de mayo del 2000. 


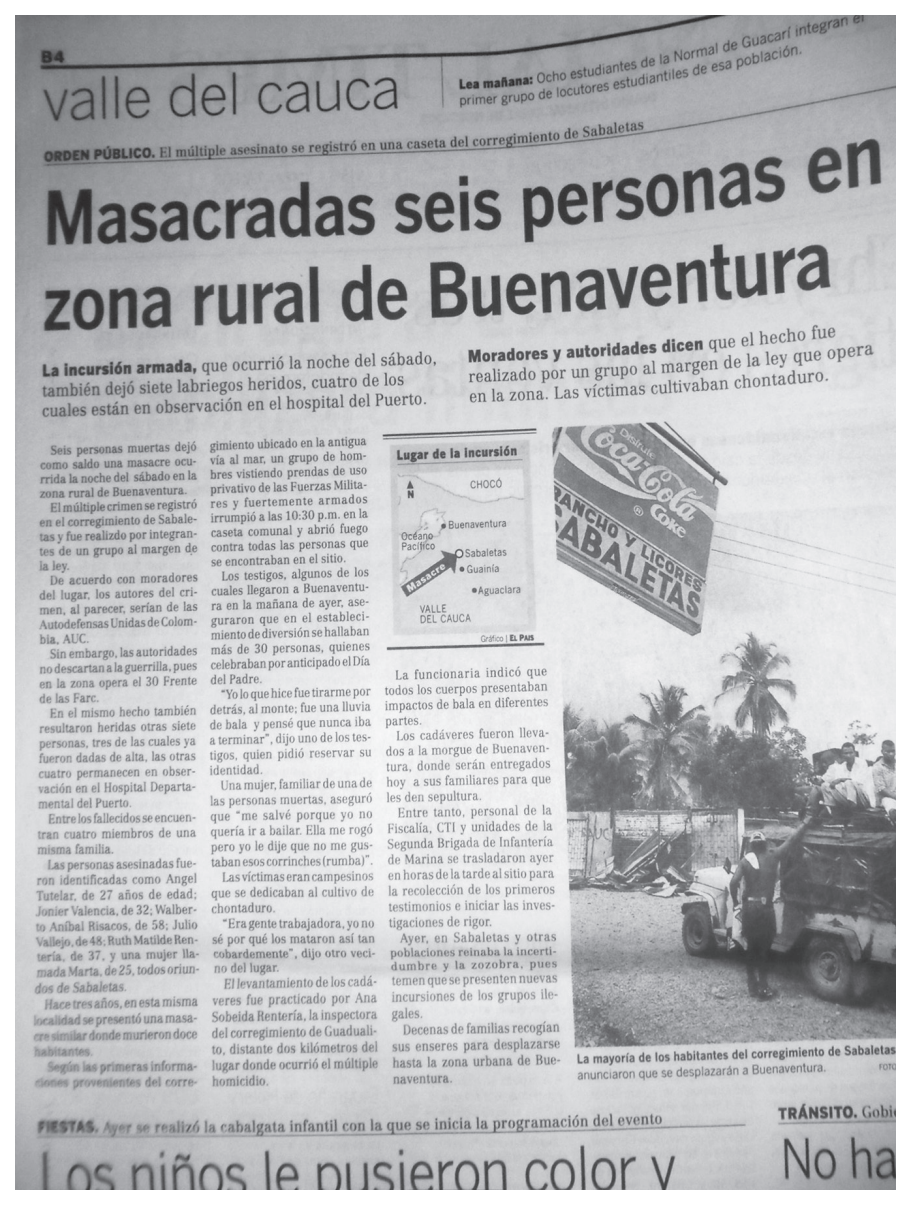

Foto No.5

Esta vez la autoría de la masacre por parte del medio se atribuye a "integrantes de un grupo al margen de la ley" y a su vez se confronta la versión de "moradores del lugar" para quienes los autores serían las AUC con la de "las autoridades" que "no descartan a la guerrilla, pues en la zona opera el 30 frente de las FARC". En adelante, el relato periodístico se centra en los testimonios de las víctimas y testigos de la masacre, pero esta vez se integran como actores a funcionarios encargados del levantamiento de los cadáveres: "Fiscalía, CTI y unidades de la Segunda Brigada de Infantería de Marina”, de acuerdo al diario. De otra parte, las víctimas se unifican bajo la categoría general de "personas", sobre las que aparte de sus nombres, edad, y detalles sobre el modo como fueron asesinados no se presenta más información.

Se apela a sí mismo al uso de un gráfico en el que se muestran los lugares donde sucedió la masacre respecto a Buenaventura, pero es imposible a partir de él inferir cualquier tipo de análisis sobre las condiciones espaciales y territoriales del conflicto. Deben destacarse dos elementos de la información que apelan a antecedentes de los eventos: por una parte, se menciona la masacre sucedida en mayo del 2000 y en una columna aledaña al texto principal se hace una esquemática cronología sobre las masacres ocurridas desde la primera incursión de los paramilitares que, de acuerdo al diario, son diez.

Al día siguiente, 17 de junio, aparece en la primera página del diario una breve nota que hace parte de una columna dedicada a los titulares en la que se destacan otras noticias del día ( $1^{\circ}$. Grado: derecho de acceso y $2^{\circ}$. Grado: jerarquización). Con una pequeña fotografía y con el antetítulo de Valle aparece el pequeño titular "Comunidad pide que la protejan”. En las páginas interiores, sección B, Valle del Cauca, el tema tiene despliegue bajo marco "Violencia" y con el título: "El miedo reina en Sabaletas" (foto No.6). En este informe ya se precisa la autoría de la masacre y se cita una fuente oficial dando el reporte de la misma: un comunicado de la Segunda Brigada de Infantería de Marina y el testimonio de su jefe, el coronel Bautista Cárcamo.

Se trata de un artículo con algunas diferencias respecto a los anteriormente reseñados. Por primera vez, es una fuente oficial la que aporta la información para la construcción del relato periodístico y la que señala a los responsables. También, por primera vez, se presenta un comentario crítico sobre lo sucedido, mencionando que se trataba de "un hecho anunciado” (defensor del pueblo). Por último, aparece el testimonio de un líder comunitario - presidente del Consejo Comunitario número 8- reclamando el hecho de que "mataron a gente inocente, pues esas personas eran labriegos sin ningún problema con nadie”. Se apela también al testimonio valorativo del obispo de Buenaventura. 
VIOLENCIA. Autoridades atribuyeron masacre de seis personas al Frente Pacífico de las AUC

El miedo reina en Sabaletas

Al Frente Pacífico de las "Este fue un hecho anunciado, pues desde hacía mucho tiempo la Autodefensas Unidas de comunidad había alertado sobre la presencia de paramilitares en la Colombia, AUC, atribuyeron zona", dijo Hernán Sandoval, defensor del Pueblo.

las autoridades la masacre de seis campesinos, ocurrida la noche del sábado en el corregimiento de Sabaletas, de Buenaventura.

Según un comunicado de la Segunda Brigada de Infantería de Marina, los crímenes fueron cometidos por doce hombres, quienes llegaron la zona a bordo de dos camperos y vistiendo prendas de uso privativo de las Fuerzas uso privativo

Igualmente, la Armada pre-

cisó que los responsables de los asesinatos iban encapuchados y llevaban una lista de las personas que iban a matar.

"Llegaron hasta una reunión que había en una espe-

cie de bar o cantina. Junta-

ron a las personas y comen-

zaron a dispararles, al pare-

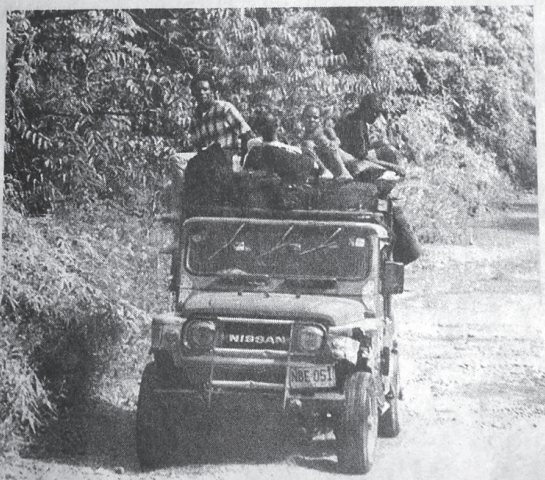

Cerca de cien personas de la zona rural del Puerto han abandonado sus tierras por temor a la violencia. en sus propias palabras

La violencia se ha vuelto a apoderar de esta carretera, como cuando la masacre del 12 de mayo de 2000"

Rigoberto Corredor, obispo de Buenaventura

sonas eran labriegos sin ningún problema con nadie" Ayer se realizó el sepelio de una de las víctimas, identificada como Walberto Anibal cada como Walberto Anibal

Para hoy se preparan las honras fúnebres de las demás personas asesinadas.

Foto No.6

Al día siguiente, miércoles 18 de junio, aparece nuevamente en la sección Valle del Cauca un artículo que ocupa por lo menos el 80 por ciento de la página, con el título "Reforzarán seguridad en antigua vía a Buenaventura" (foto No.7). Este artículo es elaborado a partir de la información emanada de un consejo de seguridad realizado en Buenaventura y que contó con la presencia del gobernador del Valle del Cauca, Germán Villegas Villegas. De hecho es él quien ocupa la mayor parte del espacio para dar cuenta de las medidas tomadas para garantizar la seguridad en la zona y evitar así los desplazamientos masivos. Ahora bien, en el conjunto de la información sobre la situación de Sabaletas se incluyen temas que no tienen que ver directamente con la masacre: estadísticas sobre delitos en el Valle durante los años 2002 y 2003, el descenso de homicidios en la ciudad de Cali y tres secuestros aislados.

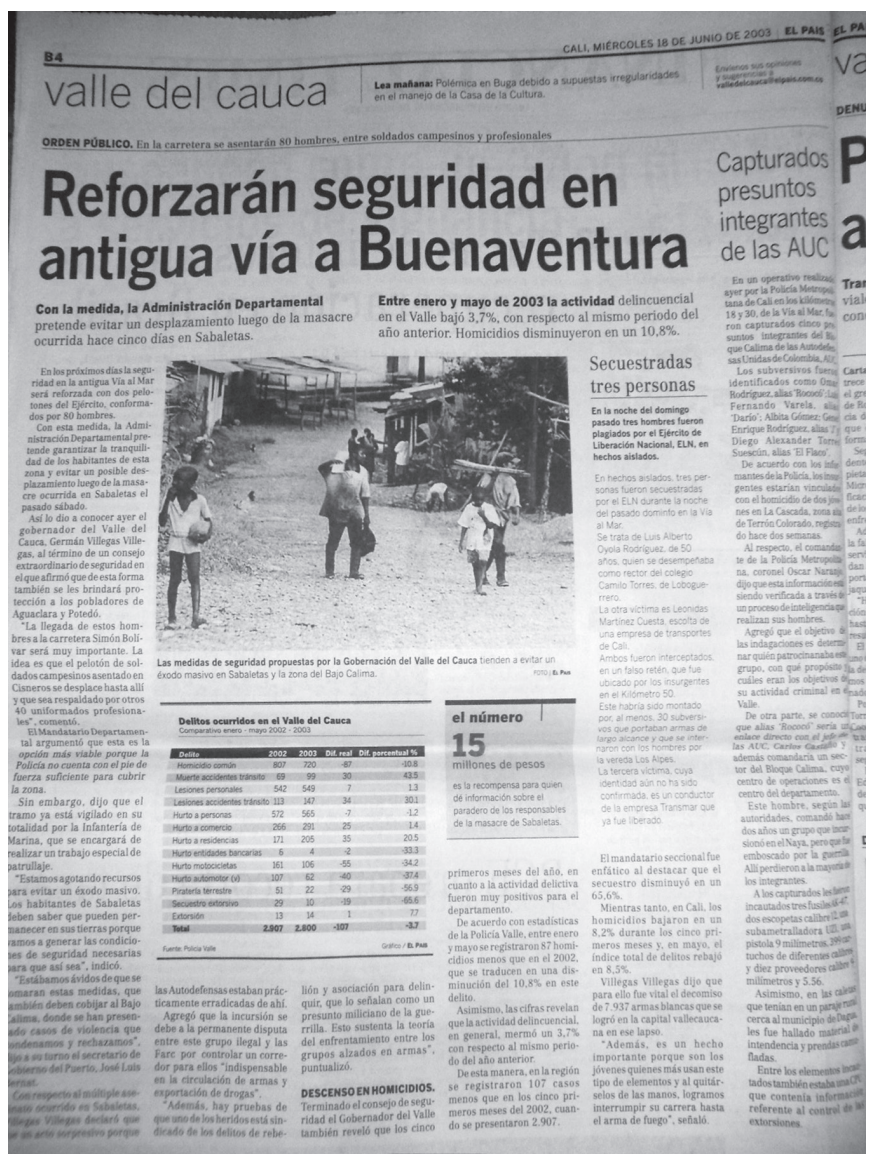


De otra parte, el periódico nacional ElTiempo hace un reporte de esta masacre solamente el día 16 de enero, en dos secciones. En la primera página aparece el breve titular "Masacre en Buenaventura" (foto No.8 y 9) y su desarrollo se presenta en la página de Información General con el título "Buenaventura. Paras mataron a 6 personas" (fotos No.10 y No.11). Contando como fuente de información solamente con el comunicado de la Segunda Brigada de Infantería, se hace un breve relato de lo sucedido esa noche y se presentan el nombre y las edades de las víctimas mortales; también se adjudica la masacre a grupos paramilitares.

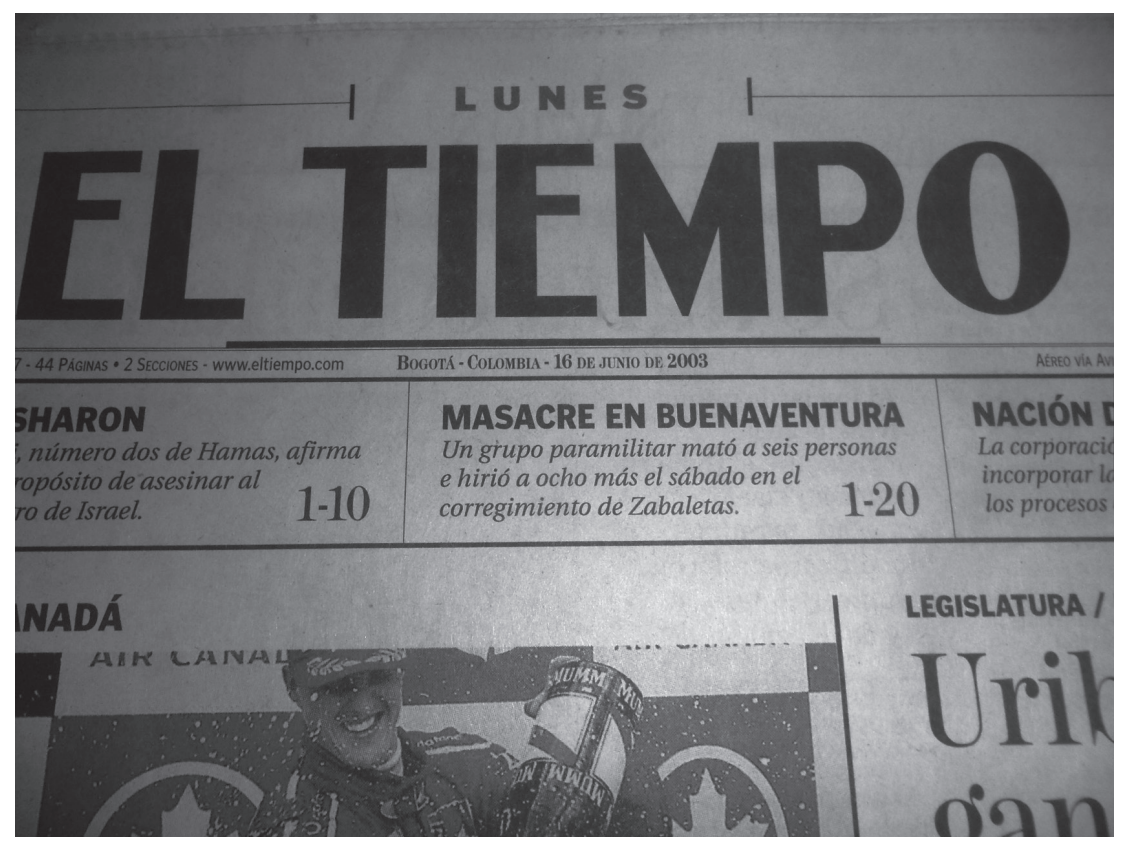

Foto No.8

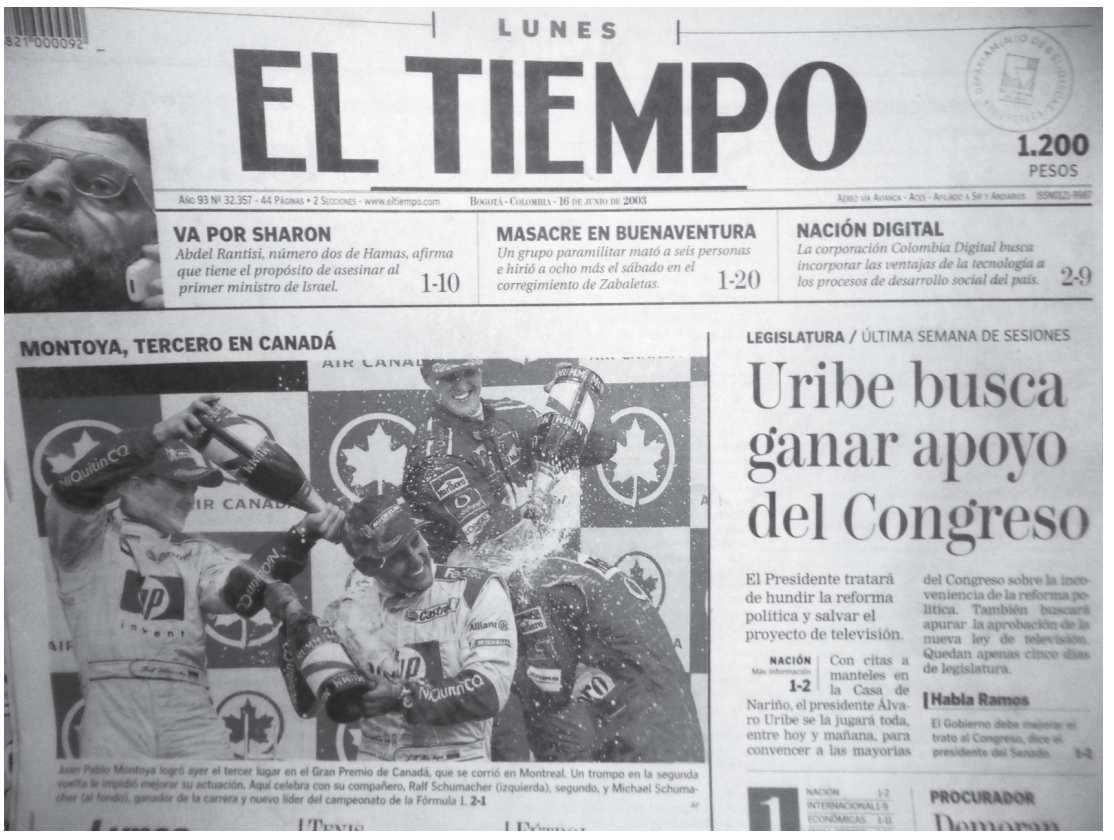


En términos del $1^{\circ}$. Grado mencionado por Alsina - el derecho de acceso- esta masacre merece una alusión en la primera página al lado de otras informaciones de orden nacional e internacional de muy diversos talantes; en ellas se destacan la foto de los campeones de la Fórmula 1, los avances del presidente del momento Alvaro Uribe para adelantar la reforma política. No obstante, el $2^{\circ}$. Grado, su jerarquización, denota poca importancia, muy a pesar de aparecer en primera página: su ubicación allí es escueta y en la página interior aparece en una extensión breve, "orillada" en una de las esquinas de la página. En términos del $3^{\circ}$. Grado, la tematización, la nota se ubica en la sección "Información general", al lado de notas positivas sobre dos empresas, una de recicladores y otra de ladrillos. De otra parte, como ya había sido mencionado, se apela a un discurso periodístico convencional, "clasico", en el que se aportan una serie de datos y se adjudican estrictamente a una fuente oficial (ver fotos 10 y 11).
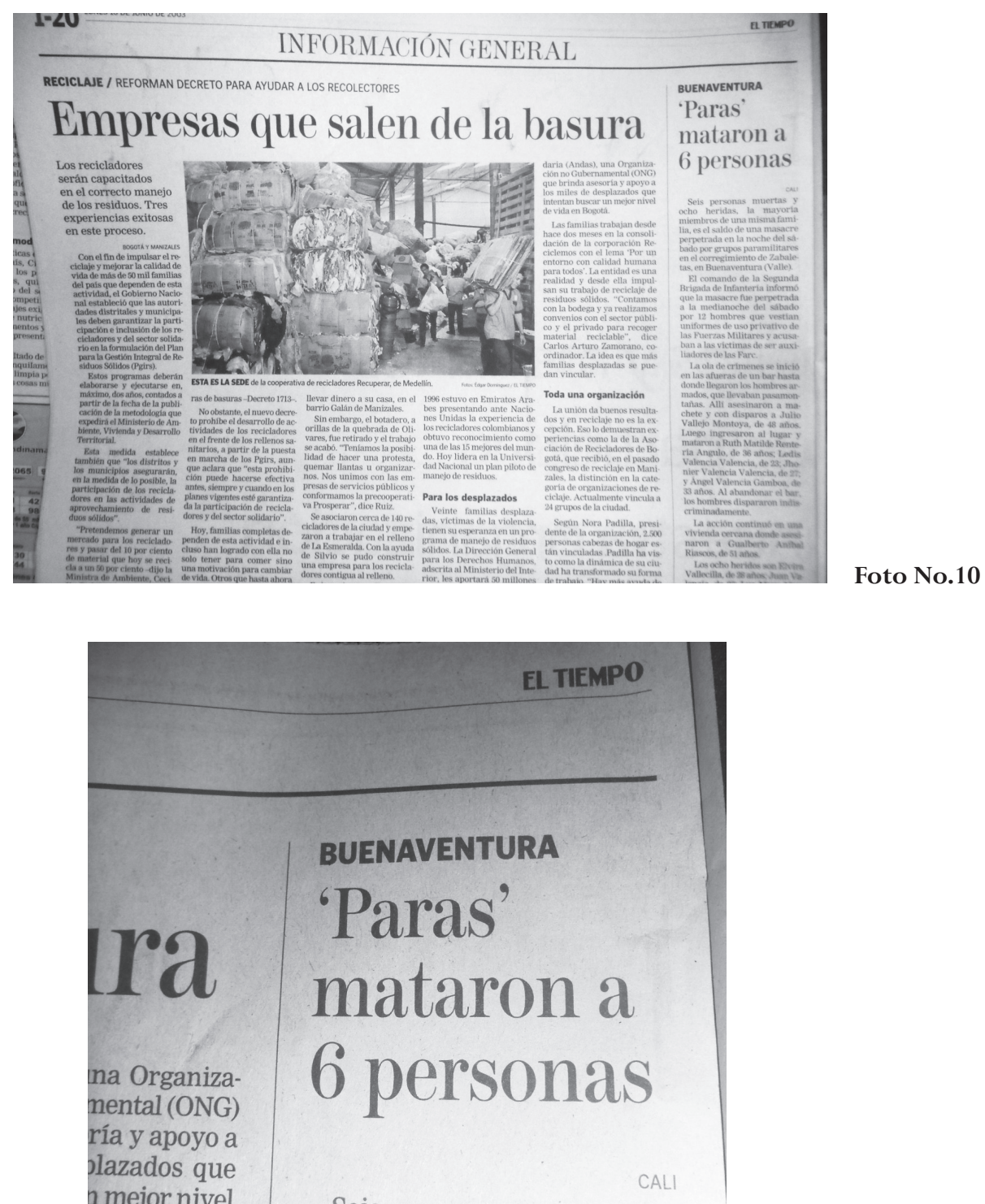
1 mejor nivel

Seis personas muertas y ocho heridas, la mayoría miembros de una misma fami- 
Para finalizar este aparte, debo advertir que las conclusiones que de aquí se derivan no pueden ser generalizadas a nivel nacional ni a nivel regional: el análisis de sólo dos de las masacres, en dos medios de comunicación no son suficientes para ello. De otra parte, desde mi perspectiva, para hacerlo no es suficiente con el análisis textual o de contenido sino que se hace necesario confrontar estos resultados con las prácticas y discursos de los periodistas encargados de procesar dicha información. Muchas de las respuestas respecto a las inconsistencias, inexactitudes o fragmentaciones derivadas de éste y otros trabajos similares sólo pueden ahondarse si se hace el ejercicio correlacionar los discursos periodísticos con las prácticas de producción.

En el caso del tratamiento de El País, el encargado de recolectar la información sobre los eventos narrados es el periodista Adonay Cárdenas (q.p.d), que trabajó como corresponsal de este diario en Buenaventura por cerca de 30 años. A propósito del cubrimiento de las masacres, en una entrevista realizada en la sede del periódico en Buanaventura, expresó lo siguiente:

Cómo aborda usted periodísticamente hablando el tema de las masacres en Sabaletas. ¿Usted cómo se entera?

Pues primeramente a uno lo llaman.

¿La policía o la comunidad?

La fuente en esa masacre fue la gente. Un muchacho David Cardona me llamó, de inmediato uno llama a la policía, para tratar de confirmar la versión y luego se hace el desplazamiento... a veces no hay logística de transporte...

¿Y usted como se desplaza?

En ese caso llego a la zona; en otros casos uno va a los barrios con cierto temor porque ya hemos tenido algunas experiencias malucas, en Lleras sobretodo, pero básicamente la información ha surgido es de la misma gente.

Una de las conclusiones que yo sacaba era que quienes cuentan y explican lo que pasó es la comunidad y que la policía solamente dice "tranquilos que ya estamos aquí pendientes"

Ya controlamos la situación.

Pero no hay explicación sobre lo que pasó.

La policía lo llama a uno básicamente cuando hay una incautación de droga, cuando hay capturas o cuando quieren un manejo de alguna cosa; en estos días me llamó el coronel para darme una información de cómo estaban compuestos los Urabeños, pero seguramente tendrá algún interés en eso; uno le colabora por mantener la fuente pero las masacres y todo eso no, antes tratan es de minimizarlas. 


\section{CONCLUSIONES}

En el caso de la comunidad de Sabaletas, las interpretaciones que circulan más allá de su comunidad sobre los eventos violentos resultan precarias y fragmentadas.

Como pretende mostrarse con este trabajo, sus pobladores han padecido una serie de transformaciones culturales, organizativas y económicas drásticas en los últimos 25 años que no se advierten en las publicaciones periodísticas analizadas. Es evidente que en el periódico El País, por sus cercanías a la zona - dado que prima el criterio de noticiabilidad de proximidad geográfica- el tratamiento informativo ha sido mayor, comparado con la ausencia de información en un caso (masacre 10 de mayo, 2000) y el pobre tratamiento en el otro del periódico nacional El Tiempo (masacre 14 junio, 2003). Puede decirse en ese sentido, que para ElTiempo, lo sucedido en un corregimiento de la costa pacífica colombiana - parte de la periferia del departamento del Valle y del país- hace parte de lo que podríamos llamar su periferia informativa, más aún cuando nos referimos a un periodo histórico del país en que eventos como los narrados están sucediendo a lo largo y ancho del territorio.

En el caso del periódico El País, debe tenerse en cuenta que ambas masacres no sólo fueron reseñadas con suficiente despliegue, sino que tuvieron una resonancia de por lo menos dos días más. Se apeló para la construcción de los relatos periodísticos a los elementos clásicos de construcción de información: el que, quien, cuando, dónde y cómo. No obstante, no se abordó suficientemente el por qué. Paradójicamente, uno de los hallazgos de este trabajo es la escasa presencia de fuentes oficiales para aportar información sobre los eventos; paradójico porque, de acuerdo a lo expresado antes, son las fuentes oficiales sobre las que - en general- tradicionalmente se fundamenta la mayor parte de las informaciones. En este caso, en cambio, son utilizadas para tres propósitos:

a. Hacer comentarios o balances generales de orden valorativo - condena o sorpresa frente a las masacres-.

b. Asegurar que las fuerzas militares garantizan la seguridad de la región y que por tanto no es necesario desplazarse de la misma.

c. Señalar a algunas de las víctimas mortales como integrantes de la guerrilla.

Se omite dar respuesta a preguntas como las siguientes:

a. De orden militar: ¿Por qué ocurrieron las masacres? ¿Por dónde entraron y salieron los actores armados? ¿Dónde estaban las fuerzas militares? ¿Quiénes son los responsables?

b. Crisis humanitaria: las menciones que se realizan sobre el desplazamiento forzado se refieren a un llamado a no dejar la zona, pero se ignoran los aspectos vinculados a la crisis humanitaria que genera esta situación: traumas psicológicos y psicosociales de la población, dificultades de movilidad, situación de los familiares de los asesinados, etc. 
c. Consecuencias sociales y culturales: No hay información sobre las consecuencias que las masacres generan en la vida cotidiana de la población: ¿Cómo cambian las relaciones sociales? ¿Quién manda ahora en el pueblo? Más allá de las expresiones de dolor, ¿qué significan para los habitantes de la zona estas tragedias?

Respecto a lo que Patrick Charaudeau denomina "fuentes ciudadanas" llama la atención que sobre ellas recae la responsabilidad de la información obtenida para la construcción del relato periodístico. No obstante, su presencia se restringe a dar cuenta de los hechos o a manifestar expresiones de dolor por lo sucedido. En ese sentido, hay una ausencia de testimonios críticos o que enfaticen en las condiciones sociales y humanitarias en que - además del miedo- queda la población. Dentro de la clasificación que hace este autor entre víctimas, testigos y reivindicadores puede advertirse lo siguiente:

a. La noción de víctima es utilizada solamente para referirse a las personas asesinadas. No al resto de la población; esto tiene implicaciones en la interpretación en torno a las consecuencias humanitarias y sociales de la tragedia.

b. Los testimonios de los pobladores se inscriben dentro de la categoría de testigos, quienes, sin mayores detalles, rostros o historias personales relatan lo sucedido. Es evidente que en una situación como éstas es importante para algunas afirmaciones guardar la identidad de los entrevistados; sin embargo, no por ello debe dejarse de lado una caracterización más precisa de ellos. c. El desplazamiento forzado que inician algunos de los pobladores puede considerarse como una variante del carácter reivindicativo expuesto por Charaudeau. Si bien no se trata en estricto de una manifestación planificada para llamar la atención de los medios o de las autoridades, sí se trata de una situación que - al ser de carácter masivo- rompe con la cotidianidad del espacio público de los municipios a los que arriban. De hecho, las notas que hacen seguimiento a las masacres se refieren justamente a los desplazamientos que se presentan al casco urbano de Buenaventura.

En términos de los grados de selección de la información mencionados por Alsina derecho de acceso, jerarquización y tematización- debe destacarse que en el periódico El Tiempo la única alusión a la tragedia se hace en la sección Información General, al lado de "notas positivas"; por el nombre de la sección puede entenderse que en ella cabe de todo. En El País, apareció básicamente en la sección regional. Tengamos en cuenta que, como se expresó en la introducción del trabajo, una de las funciones de los medios masivos de comunicación es poner en la agenda pública los temas sobre los que es necesario conversar públicamente y sobre lo que habría que decir o discutir sobre ellos (agenda setting). En ese sentido, puede derivarse que para El Tiempo se trata de un asunto de menor importancia, una especie de "caso aislado" que sucede en regiones inhóspitas y poco importantes del país. Para El País, por su parte, se trata de un evento que no se integra al devenir de la región - es algo que sucede "por allá"- y que no requiere un ejercicio de contextualización. ¿Justicia comunitaria? ¿Justicia guerrillera? 
¿Transformaciones culturales? ¿Formas organizativas? Nada de ello tiene que ver con las notas publicadas.

El ejercicio de integrar toda la reflexión y la investigación académica a los discursos periodísticos masivos cuenta con muchos obstáculos. Tiende a creerse que se trata de falta de formación y de información de los periodistas encargados de cubrir tales eventos. No obstante, esto no es del todo cierto o por lo menos no explica suficientemente el asunto; también son claves las relaciones que establecen los medios de comunicación con los agentes de poder estatal - y no estatal- en las omisiones de información, así como los criterios económicos y sus relaciones con los criterios de noticiabilidad. Para analizar este tipo de dinámicas, es urgente abordar desde diferentes aristas el tema de la libertad de información, que tiende a ser visto como un asunto en el que los periodistas y medios de comunicación son las víctimas, pero que obvia otras dimensiones vinculadas a los interese de omitir o no ciertas informaciones. El periodismo en las regiones, el periodismo de las periferias, tiene una misión que difícilmente logra: la de integrar a la vida nacional los temas que afectan a las zonas más excluidas. En síntesis, tiene un papel clave en las representaciones sociales sobre el país.

La ausencia de procesos de comunicación y de capacitación de producción de información en una comunidad como la analizada, al lado de toda la serie de dificultades expresadas respecto a la presencia de actores armados ilegales en la región hacen prácticamente impensable la posibilidad de que la misma comunidad acuda a las tecnologías de la información para producir información propia sobre su situación. Otros casos han sido exitosos en ese sentido, como por ejemplo el proyecto comunicativo de la ACIN, Asociación Nacional de Cabildos indígenas, quien cuenta con una serie de proyectos que facilitan la producción y distribución de información que denuncia la situación de la población civil respecto a los grupos armados y confronta - aunque con escasa difusión- las versiones sobre los hechos que circulan en los medios masivos de comunicación.

\section{Notas}

${ }^{1}$ Primer Gran Informe de Memoria Histórica de la Comisión Nacional de Reparación y Reconciliación Trujillo, una tragedia que no cesa. Editorial Planeta, 2a. Edición, Bogotá, 2008, pp.13.

${ }^{2}$ Dice el informe: A pesar de su escalofriante magnitud, estos datos son aproximaciones que no dan plena cuenta de lo que realmente pasó, en la medida en que parte de la dinámica y del legado de la guerra es el anonimato, la invisibilización y la imposibilidad de reconocer a todas sus víctimas. Además de la magnitud de los muertos, los testimonios ilustran una guerra profundamente degradada, caracterizada por un aterrador despliegue de sevicia por parte de los actores armados sobre la inerme población civil (GMH, 2013, p. 20).

${ }^{3}$ Estatuto de Roma de la Corte Penal Internacional. Artículos 7 y 8. 


\footnotetext{
${ }^{4}$ Para sistematizar esta caracterización se ha partido del Informe de la Comisión para el Esclarecimiento

Histórico (CEH) en Guatemala, Guatemala: memoria del silencio. Febrero 25 de 1999.

${ }^{5}$ En: Bajo todos los fuegos. Los periodistas en el conflicto colombiano. Omar Rincón y Marta Ruiz (Editores).

Proyecto Antonio Nariño, Bogotá, 2002, pp.33

${ }^{6}$ Entrevista realizada por la autora. Bogotá, julio 2013.

${ }^{7}$ Entrevista con la autora. Buenaventura, enero de 2013.
}

\section{Referencias}

Alsina, M.R. (1996). La construcción de la noticia. Paidós Comunicación. Barcelona.

Aguilera, M. (2001). Justicia guerrillera y población civil. 1964 y 1999. En De Sousa S. y García V. (eds), El caleidoscopio de las justicias en Colombia. Bogotá, Tomo 2. Colciencias/ ICANH/CES/Uniandes/ UN.

Aguilera, M (2014). Contrapoder y justicia guerrillera. Fragmentación política y orden insurgente en Colombia (1952- 2003). Bogotá, Iepri, Debate y Universidad Nacional de Colombia.

Alzate, P. (2010). Libertad de prensa en el Valle del Cauca. Un análisis descriptivo a partir de las cifras de la Fundación para la Libertad de Prensa. Revista Nexus, 8, 86- 101.

Caicedo, R. D. (2007). Los únicos muertos que pueden caminar. (Monografía de trabajo de grado inédita). Programa de Sociología, Universidad del Pacífico, Buenaventura.

Charaudeau, Patrick (2003). El discurso de la información. La construcción del espejo social. Barcelona, Gedisa. Estatuto de Roma de la Corte Penal Internacional.

http://www.un.org/spanish/law/icc/statute/spanish/rome_statute\%28s\%29.pdf

Espinoza, N. (2009). El campo jurídico del 'otro derecho' en la Sierra de la Macarena. Elementos para un análisis crítico de la justicia alternativa en una zona de fuerte conflicto armado. En: Revista colombiana de sociología, vol.32, julio- diciembre.

Feierstein, D. (2007). El genocidio como práctica social. Entre el nazismo y la experiencia argentina. Buenos Aires, Fondo de Cultura Económica.

Fundación para la Libertad de Prensa (2012). Entre el silencio y el coraje. Dos décadas de libertad de prensa en Colombia. Bogotá, Planeta.

Gordon, D. (2011). La fotografía como constructora de memoria en el conflicto armado. Una experiencia de intervención social en la comunidad de Sabaletas, Valle del Cauca. (Monografía de trabajo de grado inédita). Escuela de Comunicación Social, Universidad del Valle.

Grijelmo, Alex (2012). La información del silencio. Cómo se miente contando hechos verdaderos. Madrid, Taurus.

Grupo de Memoria Histórica (2013). ¡BASTA YA! Colombia: Memorias de guerra y dignidad. Bogotá, Imprenta Nacional.

Guzmán, A y Moreno, R. (2007). Autodefensas, narcotráfico y comportamiento estatal en el Valle del Cauca. Parapolítica. La ruta de la expansión militar y los acuerdos políticos. Corporación Nuevo Arco Iris (eds), Bogotá, Intermedio Editores.

Informe de la Comisión para el Esclarecimiento Histórico (CEH) en Guatemala, Guatemala: memoria del silencio. Febrero 25 de 1999.

Kalyvas, S. (2001). La violencia en medio de la guerra civil. Revista Análisis Político, 42, 1 - 25.

Merry, S. E. (2003). Una clasificación de la justicia popular. El Otro Derecho, 30, Bogotá, 40- 74

Misión de Apoyo al Proceso de Paz Mapp- OEA (2011). Identidad e imágenes, Sabaletas un pueblo con memoria. Cali, Equilibrio Gráfico Editorial. 
Primer Gran Informe de Memoria Histórica de la Comisión Nacional de Reparación y Reconciliación (2008). Trujillo, una tragedia que no cesa. Bogotá, Editorial Planeta.

Rincón, O y Ruiz, M. (eds.) (2002). Bajo todos los fuegos. Los periodistas en el conflicto colombiano. Bogotá, Proyecto Antonio Nariño.

Segundo Gran Informe del Grupo de Memoria Histórica de la Comisión Nacional de Reparación y

Reconciliación (2009). La masacre de El Salado, Esa guerra no era nuestra. Bogotá, Editorial Taurus y Fundación Semana.

Uribe, M.V. (1975). “Matar, rematar y contramatar. Las masacres de la violencia en el Tolima (1948- 1964)”. Bogotá, Cinep.

\section{Páginas de internet}

\footnotetext{
Oficina Gestión de Paz y Convivencia de la Gobernación del Valle (2004). Diagnóstico de la población en situación de desplazamiento - presentada en el municipio de Buenaventura. Recuperado de www. valledelcauca.gov.co/gestionpaz/descargar.php?id=970 Gobernación del Valle (s.f.).

http:verdadabierta.com. http:/ / rutasdelconflicto.com/
}

\section{Periódicos}

El País de Cali, ElTiempo y El Puerto (mayo y junio de 2000, y junio y julio de 2003).

Recibido: abril 30 / Aprobado: junio 1 de 2015 